MIDAS

Museus e estudos interdisciplinares

1 | 2013

Varia

\title{
Henrique Coutinho Gouveia - Museu Etnográfico da Madeira: estudo de um modelo de avaliação
}

\section{Luís Pequito Antunes}

\section{OpenEdition}

Journals

\section{Edição electrónica}

URL: http://journals.openedition.org/midas/166

DOI: 10.4000/midas. 166

ISSN: 2182-9543

\section{Editora:}

Alice Semedo, Paulo Simões Rodrigues, Pedro Casaleiro, Raquel Henriques da Silva, Ana Carvalho

\section{Refêrencia eletrónica}

Luís Pequito Antunes, "Henrique Coutinho Gouveia - Museu Etnográfico da Madeira: estudo de um modelo de avaliação », MIDAS [Online], 1 | 2013, posto online no dia 11 abril 2013, consultado no dia 22 setembro 2020. URL : http://journals.openedition.org/midas/166 ; DOI : https://doi.org/10.4000/ midas. 166

Este documento foi criado de forma automática no dia 22 setembro 2020.

\section{c) (i) (2)}

Midas is licensed under a Creative Commons Attribution-NonCommercial-ShareAlike 3.0 International License 


\title{
Henrique Coutinho Gouveia - Museu Etnográfico da Madeira: estudo de um modelo de avaliação
}

\author{
Luís Pequito Antunes
}

\section{REFERÊNCIA}

Gouveia, Henrique Coutinho. 2009. Museu Etnográfico da Madeira: estudo de um modelo de avaliação. Praia e Tomar: Universidade de Cabo-Verde e Instituto Politécnico de Tomar. 253 páginas, ISBN-978-972-9473-38-8.

1 A avaliação de instituições, projetos e programas é hoje corrente, tendo transitado das organizações privadas para a administração pública. Nos últimos anos assistimos na área da cultura a uma generalização das avaliações, nomeadamente nas bibliotecas, focalizadas na melhoria dos serviços e na satisfação do consumidor final - o cidadão/ cliente. Foi com este propósito que Henrique Coutinho Gouveia desenvolveu ao longo de seis itens o fio condutor da avaliação, traçando um quadro de situação em que identifica os pontos fortes e fracos, as fraquezas e as oportunidades do Museu e propõe as soluções adequadas e necessárias à mudança na dupla perspetiva de antropólogo e museólogo. Ao longo desta obra o Autor sugere amplos motivos para uma discussão teórica que visa enriquecer um debate que, mais tarde ou mais cedo, terá que ser feito em torno dos "modelos de avaliação" dos museus portugueses.

2 Os dois primeiros pontos - justificação e finalidades da missão e Museu Etnográfico da Madeira, breve historial - servem de enquadramento ao diagnóstico efetuado e dão a conhecer ao leitor a génese da proposta museológica, as razões inerentes às dificuldades surgidas na sua implementação e os contextos em que os referidos obstáculos surgiram.

3 Ao iniciar a análise pelo historial da instituição o Autor pretendeu dar visibilidade às razões estruturais que, podíamos dizê-lo, caracterizam o desenvolvimento da maioria 
dos museus portugueses. Senão repare-se. A ideia de criação do Museu Etnográfico da Madeira remontaria aos anos sessenta por iniciativa de um grupo de ilustres madeirenses e destinar-se-ia a preencher uma lacuna na salvaguarda do património do arquipélago e a servir como atrativo para os visitantes nacionais e estrangeiros (p. 19). Seguir-se-ia um período preparatório "bastante dilatado" (p. 38) conducente à sua organização que finalizaria em junho de 1996, com a inauguração oficial do Museu.

o quadro traçado anteriormente tem paralelo com outras situações conhecidas. Entre os exemplos possíveis referimos apenas três. Um é o Museu Marítimo e Regional de Ílhavo. Pensado nos anos vinte e tendo como antecedente próximo uma exposição realizada no início dos anos trinta abriria ao público em 1937, datando as atuais instalações de 2001. Outro é o Museu Municipal de Almada. A ideia de criação data de meados dos anos cinquenta por iniciativa da Comissão Municipal de Arte e Arqueologia mas só em 1976 seria objeto de uma proposta formal para a sua fundação pela Comissão Administrativa, embora a sua efetivação se tenha concretizado em 1984. E, por fim, o Museu Municipal de Portimão. A proposta de criação data de 1983, tendo o edifício para a sua instalação sido comprado em 1996 e sujeito a obras de construção e reabilitação que adiaram a sua inauguração para maio de 2008.

5 Encontramos aqui um primeiro comportamento padrão que é simultaneamente um ponto fraco: dificuldade de concretização dos projetos em tempo útil. As justificações são variadas desde a ausência de vontade política ou de um plano museológico até à falta de instalações, passando pelas conhecidas dificuldades financeiras.

6 A ideia inicial de criação ou fundação de muitos museus começa por ser uma vontade agregadora de intenções que necessitam de ser viabilizadas. A constatação quase imediata de que é necessário mais do que "desejar" leva a um impasse. Neste ponto são várias as combinações, nem sempre fáceis de conciliar: inexistência de coleções com existência de instalações; existência de um programa museológico com ausência de vontade política ou, noutra variante, falta de financiamento, entre muitas outras combinações.

7 Qualquer que seja a razão o desfasamento criado conduz de imediato à desatualização do programa museológico e à sua descontextualização. Ora o que acontece frequentemente é os políticos e por vezes os técnicos quererem, passados vários anos, implementar esses planos como sendo "novos" sem procederem a uma avaliação da sua atualidade ou, mesmo, pertinência já que uma simples "revisão" do programa inicial nem sempre é o suficiente.

8 A demora na implementação do projeto a par da evolução do panorama museológico madeirense acabou por dificultar a sua concretização. A criação de outros estabelecimentos museológicos não só alterou os interesses em jogo como retirou protagonismo à instalação do museu etnográfico. Este longo período preparatório sujeito a avanços e recuos, a par da indefinição sobre a localização e escolha das instalações teve consequências diretas sobre o acervo, acabando por "contribuir sensivelmente para a sua degradação e perda de exemplares tendo os problemas surgidos chegado a ter eco na imprensa local" (p. 45).

9 Nos pontos 3 e 4 - Programação: objetivos e atividades e Organização funcional e instalações o Autor identifica de forma muito esclarecida a relação existente entre causa-efeito, alertando para as respetivas consequências ao mesmo tempo que procura construir "um modelo de estudo e diagnóstico" do Museu Etnográfico da Madeira. 

ação à qual nunca é demais chamar a atenção. Trata-se do sistema de registo das coleções. Ao tratar este tema é evidente a conjugação de dois interesses caros ao Autor: a museologia e a antropologia. Facto que possibilita uma perceção muito clara ao leitor dos aspetos relacionados com a captação e registo da informação pelo museu e o levantamento e tratamento da informação recolhida no campo pelos coletores. coleções, no caso em apreço ainda manual, e da primeira medida de conservação e salvaguarda do património à guarda dos museus, encontrando-se, em muitos casos, secundarizada em relação a outras funções. O Inquérito aos Museus Portugueses (OAC/IPM 2000) a propósito desta matéria refere que o «inventário sumário» é a modalidade mais 
frequente. Dados que o Panorama Museológico em Portugal [2000-2003] (OAC/IPM 2005) confirmam sem registar alterações significativas.

Ao longo de doze páginas (da 131 à 154) o Autor faz um levantamento minucioso da situação encontrada no que respeita ao sistema de registo dos testemunhos em causa, relacionando-o com a política de incorporação.

Se consideramos que a documentação das coleções é toda a informação que um museu possui sobre os bens à sua guarda um sistema de registo não deverá ser tido como uma tarefa administrativa mas como uma atividade científica que se ocupa dos conteúdos informativos com vista à recuperação e divulgação da informação. As omissões e insuficiências diagnosticadas pelo Autor são as mesmas que, de uma forma geral, se encontram noutros museus portugueses resultantes de uma prática cuja análise é complexa.

O facto da informatização dos sistemas de registo ser hoje comum não simplifica a situação. Primeiro porque a fase de transição se tende a prolongar fazendo coincidir os dois tipos de registo. Em 2002, segundo as obras citadas, apenas 10,5\% dos museus tinham o inventário informático completo, em 35,7\% estava em curso e 51,3\% afirmavam não ter. Note-se que estes valores não se alteram entre 2000 e 2002. Segundo porque a opção por sistemas informáticos deve ser, conforme o Autor refere, precedida de uma reflexão que tenha em conta o uso de standards e um domínio terminológico dos temas a tratar, bem como uma ampla participação dos profissionais.

21 Ao longo do terceiro e quarto ponto o Autor traça com vigor e acerto crítico os aspetos tratados desde a receção de visitantes aos recursos humanos, passando pela exposição, serviços educativos, atividades editoriais, componentes comerciais à conservação e recursos humanos. O diagnóstico delineado alcança não só o objetivo proposto como permite tomá-lo como referência para eventuais estudos a fazer para outros museus.

Finalmente no ponto 5 - Propostas de reorganização do estabelecimento - o Autor deixa em aberto as opções a tomar não induzindo uma escolha única. A razão apresentada reside no leque de problemas tratados e cuja solução não é de molde a conferir uma só opção.

23 A proposta de reorganização apresentada introduz uma alteração na metodologia seguida ao inverter a ordenação da análise efetuada até agora. Segundo o Autor a prioridade deveria radicar nas áreas de retaguarda por se encontrarem aí as insuficiências mais gritantes como "também porque se está perante setores de base de cujo relacionamento dependem em grande parte as atividades de relacionamento com o público" (p. 165). Ora, não devemos esquecer que os museus existem para servir os públicos e é em função disso que devem desenvolver a sua missão e prestar um serviço público de qualidade.

24 Os cenários traçados induzem a uma reflexão sobre a missão do museu. Esta deve ser definida com base num amplo consenso entre políticos, técnicos e as partes interessadas. A razão é simples. Os objetivos estratégicos são definidos a partir da declaração da missão, logo esta deve conter a razão de ser do museu, o que faz e para quem faz, de forma a colher o envolvimento de todos e a garantir os interesses do público. A experiência diz que por muito bons que os projetos sejam, não avançam sem que o poder político - central, regional ou autárquico - se reveja neles. A relação entre a política e o património está, por assim dizer, sempre presente. 
25 A partir da definição de objetivos e vetores de intervenção o Autor aborda as alterações no que respeita às instalações, reservas, incorporação e registos, conservação, política de exposições, educação, divulgação e edições, estratégia comercial e recursos humanos. Ao usar o termo educação, em vez de serviços educativos, o Autor remete para o papel dos museus enquanto recurso educacional não-formal e ao longo da vida, dando ênfase a uma função que ultrapassa o papel instrumental dos serviços educativos. Não basta uma estrutura organizada, dotada de recursos humanos, sob a tutela do museu para existir um projeto educativo e pedagógico de cariz museológico.

Poder-se-á dizer que este olhar de Henrique Coutinho Gouveia sobre o Museu Etnográfico da Madeira é pertinente e inovador porque não se trata apenas do estudo de um modelo de avaliação da instituição mas de uma abordagem analítica, global e esclarecida feita com recurso permanente à história de vida do museu e que disponibiliza um conjunto de cenários de reconversão que traduzem o contributo da "transposição para o plano aplicado da reflexão teórica". Por todas estas razões se recomenda a sua leitura.

\section{AUTORES}

\section{LUÍS PEQUITO ANTUNES}

Centro de Estudos de História e Filosofia da Ciência (CEHFCi) da Universidade de Évora, Portugal, luispequito@netcabo.pt 